\title{
Māori parenting, from deficit to strength
}

\author{
Anaru Eketone
}

Anaru Eketone (Ngäti Maniapoto, Waikato) is a lecturer in the Department of Sociology Gender and Social Work at the University of Otago and is the father of two adult daughters.

(This article was originally accepted for publication for Te Komako, 2008).

We have all grieved, been enraged and depressed about the death of Māori children at the hands of whānau. We can all name Māori children who have become terrible bywords for the failure of some Māori families to protect and nurture their children.

Over the years the recurring response has been to call for Māori families to take greater responsibility for both their actions and their whānau with parenting courses promoted as one of the 'across the board' solutions. In light of this a brief survey was done in 2003 to see what parenting information was available to Māori parents from the main social service agencies and information providers in Dunedin. Early on it was obvious that there was very little information specifically for Māori families and so the search was widened to look at what was available generally in Dunedin. This was not intended to be a rigorous quantitative study, but the numbers do give an indication of what resources were easily available to parents.

In all, 12 Dunedin information, health and social service providers were visited to see what was available to parents on parenting skills. Having been involved in health promotion, social work and a number of local community groups, I was confident that I had approached most of the likely organisations that would be expected to either provide, or have links to those providing parenting information to Dunedin parents.

Four of the providers ran courses for parents and information was gathered on the topics covered. Plunket ran a six-week course for parents of toddlers that covered issues such as toileting, nutrition, positive parenting, play, development and safety. Barnardos ran two courses, one on family financial management, and a five week course entitled, 'Parenting with less stress and more enjoyment'. Catholic social service ran three courses based on its 'Parenting Positive Families' formula for parents with children under five, primary school age children and teenagers. The Family Care Centre ran a course called 'Caring with confidence'. No course was targeted specifically at Māori families.

From the 12 agencies 21 pamphlets, posters, books and videos were available on parenting skills. In all there were only six resources on parenting skills that were aimed specifically at Māori families. Two were from the Children's, Young Persons and their Families services and focused on positive things to do with children. The other four were focused on smacking and physical abuse. Three of these were from the Office of the Children's Commissioner, the other, a video was from the Children and Young Persons Service. (This was a parallel video 
put out for Māori parents to the mainstream one on smacking. The mainstream video focused on real parents and how they dealt with discipline. The scene that stood out to me was a Pākehā father breaking down in tears admitting that he had smacked his child. The Māori version used actors where the woman in the story eventually beats her son to death.)

In all there were 28 resources or programmes available to parents. Six were targeted specifically at Mãori and 22 were targeted at the general public. Each resource was assessed to ascertain the general themes and fell into three broad categories: communication, child / adolescent development and discipline.

\section{Communication}

Of the mainstream items $68 \%$ (15 of 22) dealt with issues of communication between parents and children. They discussed the importance of communication and/or gave examples of how parents could communicate with their child. However, only 33\% (2 of 6) of the Mãori items discussed communication.

\section{Child/adolescent development}

Of the mainstream items, 55\% (12 of 22) provided information on the physical, psychological and emotional development of children. None of the six items aimed at Māori parents discussed any issues regarding any form of child or adolescent development.

\section{Discipline}

Of the mainstream items 60\% (13 of 22) discussed issues of discipline. This included discussion on the value of discipline, as well as skills to train and correct children. Of the items aimed specifically at Māori parents, $100 \%$ (6 of 6) gave information on how to discipline children. This survey was done when it was still legal for parents to physically discipline their children and found that on the issue of physical discipline $41 \%$ (9 of 22) of the mainstream items discussed the issue of smacking whereas 66\% (4 of 6) Māori items spoke out against smacking. Of the 22 mainstream items 4\% (1 of 22) were specifically on smacking whereas for the Māori items $66 \%$ (4 of 6 ) had smacking and/or violence against children as the dominant issue.

Therefore, to summarise, of the items that I was able to locate on parenting skills amongst 12 agencies in Dunedin, there were definite trends as to what were considered issues for parents. For those who prepared, wrote and published these items aimed at a mainstream audience, $68 \%$ discussed communication between the parent and child, $55 \%$ discussed child or adolescent development, $60 \%$ discussed issues around discipline, with $41 \%$ discussing physical discipline issues. However, for those organisations who published material for Māori 33\% discussed communication, none discussed child/adolescent development and $100 \%$ focused on discipline.

The organisations who decided to provide parenting information for Māori parents obviously felt that the primary issue that Māori parents should focus on was discipline and particularly not smacking their kids. Much of this is undoubtedly driven by the perception that Māori are a violent people and somehow the Government has to do something about it. Statistics such as 48 of the 103 children murdered between 1990 and 2001 being of Mãori descent (Collins, 2006) obviously have something to do with that. No mention of course or acknowledgement of the hundreds of thousands of children that managed to somehow survive being brought up in Māori families. 
We can all remember such names as Craig Manukau, Delcelia Witika, Lillybing, Nia Glassie and the Kahui twins, but similar murders by Pākehā do not come under the same scrutiny, neither are their names repeated seemingly endlessly in the media. The media selects which crimes it will highlight often from a racist slant (Stewart-Harawira, 1997). This is a continuation of what Narayan (1995) refers to as a Colonial Rights and Care Discourse where the paternalistic guidance of the nation portrays itself as promoting the welfare of the colonised while at the same time marginalising them as 'the other', as deviant and in need of instruction. It also justifies the removal of rights that other citizens have by placing them under greater scrutiny. Greater scrutiny from the Government and its agencies, but also greater scrutiny from the media and mainstream public. This greater scrutiny from the media may in part be due to the open grieving of the tangi over a number of days compared to the brief funeral service of other cultures. This enables the story to have 'legs', in other words there is something new to add to the story from the previous day and so extends the amount of time the tragedy is in the public eye. However, this does not account for all the coverage.

The coverage of the tragic deaths of non-Māori children only seems to have 'legs' if their murderer remains at large. Therefore the names of non-Māori children that are familiar such as Coral Burrows and Teresa Cormack are well known because of the hunt for their killers. Their murders didn't bring the same criticism of Pākehā culture as Māori murders do, they were seen as the violent acts of deviant individuals and not as representatives of a deviant culture.

The media has become so fine-tuned to this reporting imbalance that it has developed various codes to let people know that a dead child is Māori. For example in 2007 some of the signals that a Māori child had been killed by members of their own family included:

... police are talking to her kohanga reo... (NewstalkZB)

...the tangi will be held at ...

... members of her whānau are gathering...

... or they give the child's full name if the Christian and surname are English names but the middle name is Māori. We all know how to listen carefully for clues as to whether the child is Māori or not, and the media make every attempt to let us know.

The coded messages do not stop there. Christine Rankin's statement about child abuse where she said that 'we have got a problem with Mãori' (TVNZ, 2007) was a highly ambiguous statement with two totally different sets of assumptions.

When someone says that child abuse is a Māori problem are they saying that there is a problem with Māori culture that allows or condones the abuse of children, or are they saying that there is a problem within Māori society or communities?

If you approach the issue from the viewpoint that there is a problem within a number of Māori communities or society, it is still possible to use the culture to bring about change.

If, however, you are saying that it is a problem with Māori culture, then by implication you are signalling that the answer to the problem cannot come from within the culture. It implies that the culture, the norms and the values need changing, therefore change must 
come from ideas and values that come from outside the culture. In other words it needs another form of colonisation to occur, this time a colonisation of values.

It is within the interest of the dominant culture to portray Māori culture itself as being deficient because it maintains a feeling of superiority (Narayan, 1995). It means that Māori continually need the coloniser because we can't deal with these things on our own. Another consequence of highlighting poor Māori statistics is that it hides their own failures. If they can say that Māori are failing and Māori should do something about it, it diverts attention from their own failures where the mainstream public, in a way, become satisfied because they think, 'at least we are not as bad as them'.

This idea is taken even further by groups who wanted to regain the right to smack their children. Presumably they see child abuse as a Māori problem, so when a recent initiative from the Children's Commissioner recommended screening every home, the Families First coalition decried it as targeting 'good law-abiding parents' when its attempts should be aimed at the other at-risk type families (Family First, 2007). Again 'good law-abiding parents' can be interpreted as code for middle-class white families, and the 'other' is of course brown families.

If there is this prevailing idea that Pākehā parents are good and the bad ones are brown it raises the question of who is in the firing line now the so-called anti-smacking legislation is firmly in place. We also have the priorities of the Children's Action Plan from the White Paper on Vulnerable Children (Ministry of Social Development, 2012) with its supposed 'child centred' approach which could be in danger of being more of an 'agency centred' approach. Whānau Ora is making some good progress in our local community and nationally but when there is a perception that a certain area of the community is more likely to produce bad outcomes then the authorities become more aggressive in policing those populations and they also become less compromising with suspects (Newbold, cited in Bradley, 1999). Māori should continue to be wary of legislation, policy and programmes that allow for more surveillance of Māori.

If Māori parenting is framed as inferior and violent it becomes a significant issue for the practice of social work. There is widespread evidence of stereotyping occurring in the perception of professionals in dealing with minority cultures (Durie, 2001). Mental health care professionals have been shown to be more likely to have negative stereotypes of Māori than Pākehā. Therefore, they have been shown to be far more likely to consider actions by Māori as threatening or intimidatory than Pākehā who make the same statement, have the same body language or tone of voice (Durie, 2001). Consequently, it is logical to assume that because Mãori have a greater negative stereotyping when it comes to parenting, social workers are more likely to place into care Māori children than Pākehā children, when faced by the same circumstances.

This can be complicated by differences in public parenting practice. For example, when in a public situation, I regularly spoke to my children in a far gruffer manner than I did when I was at home. I have noticed this amongst other Māori parents as well (I'm not really sure why). This can also provoke negative reactions in observers from a Eurocentric viewpoint where they may be drawn to think, 'if this is the way they talk to them when I'm here, how on earth do they talk to them when I'm not here?' When in my case the reality was the opposite, I was far more civil at home. However, my own observation shows the converse to 
be true amongst some Pakeha parents. In public they speak in a far calmer tone of voice when viewed by others, than when they are in private.

Because Māori parenting is defined by discipline and violence issues, any voice that does not fall into that paradigm is either ignored or forced back into discussions on violence. Any discussion on parenting skills for Māori is forced to deal with discipline issues in the context of child abuse, before it can take a position that is not based on deficit models. It is a barrier that keeps Māori in what Paparangi Reid (1997) refers to as 'survival mode' rather than allowing the resources and the people to move on to 'development mode'.

Māori need to reclaim the parenting skills space in the public sphere and reframe the debate from a negative one based on perceived Māori failure, to a genuinely child-focused one. In a discussion with Antonio Seuli when he was part of a local Pacific Island resource centre, we both noticed how the vast majority of parenting information targeted at our two communities was based around not using physical punishment when disciplining children. He said there's nothing there on taking your kids on picnics or fishing or doing positive things, it's all about not hitting your kids (Personal communication, 2003).

Of the seven parenting skills courses that I found, only one, the Toddler Training Course delivered by Plunket, focused attention on the child in its name or advertising. Every other programme was focused on the parent, and what they needed. The problem with this approach is that the people who really need the skills are marginalised by the idea that parenting courses are for 'losers'. There is a perception that you only go to a parenting course because you are a failure or are not coping. From my experience as a facilitator of parenting courses for nearly four years, the ones who fill the parenting programmes are usually the ones who are already doing a good job, and that they are in 'development mode' wanting to do even better and spend the first session making sure that everyone knows they are coping and that they are there 'really only there to learn more'. The only exception to this was a 'Tough Love' course I assisted in where it was an accepted fact that you were there because you weren't coping with your teenager.

That is not to say that parenting courses are of limited use. Most parenting courses appeared to contain variations of the same themes looking at communication, discipline, development issues, specific skills to get co-operation/obedience and again from my own experience contain elements that many parents find very useful. However, from the outside they look as though they are operating from a deficit model and are unlikely to attract Māori parents.

The only exception to this is a programme I invited to be hosted in my home in South Auckland entitled 'How to help your child say 'no' to sexual pressure' (McDowell, 1987). Although the content was similar to many other parenting courses, its point of difference was in the name. Its stated focus was on the child rather than the parent and this changed the whole dynamic of the course. As a result most of the families that attended were Mãori and there was no stigma attached. It is also the only parenting course I have been involved in that had more than one male; in fact, from memory, there were four Māori fathers there.

In the year 2000 I was part of a small group that wanted to change the dynamics of parenting programmes by shifting this focus from the parent to the child. The programme was 
going to be based around the concept of teaching parents how to protect and enhance the mana and tapu of their children. As such it was ignoring deficit approaches that marginalise and stigmatise parents and was coming from a developmental approach that parents could identify with and feel less threatened about attending. Unfortunately, resource and personnel changes meant that the programme did not go ahead. However, I am firmly convinced that the ethos is still valid and still has the potential to make a contribution to Māori families.

\section{Conclusion}

While the focus on child abuse prevention is important, there is a danger of causing Māori parents who need help to go to ground, particularly if they fear interference from Child, Youth and Family or the police.

We need to continue reframing the debate from a deficit approach to a strengths one. We also need to change the focus of our parenting programmes from one that focuses on parents that is perceived as being for losers, to one that is child development centred, that attracts people because the focus is on what they can do for their child. Changing the focus will help remove the stigma of attending and change the focus to one of whānau development and child development.

For 10 years I was a youth worker in South Auckland. During that time I did not meet one parent that I thought didn't genuinely care for their child. What they lacked was a combination of skills, strategies, energy, resources and confidence. In my opinion what was needed was a child development approach that uplifted their mana and used the strengths they already had.

\section{References}

Bradley, K. J. (1999). Motivations for instrumental violence in 'psychopathic' offenders: A new look. Psychology: University of Auckland.

Collins, S. (2006). Symbolic act to put lid on family violence. New Zealand Herald, June 22, 2006.

Durie, M. (2001). Mauriora: The dynamics of Māori health. Auckland: Oxford University Press.

Family First. (2007). Commissioner promotes ultimate nanny state. Media release, Family First New Zealand, retrieved from http: / / www.familyfirst.org.nz/index.cfm/media_centre/media_releases.

McDowell, J., (1987). How to help your child say 'no' to sexual pressure. Waco, Texas: Word Books.

Ministry of Social Development. (2012). Children's action plan. The White Paper for vulnerable children. Retrieved from http: / / www.msd.govt.nz/documents/about-msd-and-our-work/work-programmes / policy-development/ white-paper-vulnerable-children/white-paper-for-vulnerable-children-childrens-action-plan-summaries. pdf.

Narayan, U. (1995). Colonialism and its others: Consideration on rights and care discourses. Hypatia, 10(2), pp. 133-140.

NewstalkZB. (2007). Police say child abused by extended family. 26 July 2007. Retrieved from http: / / www.newstalkzb. co.nz/ newsdetail1.asp?storyID $=121499$.

Rei9d, P. (1997). PUBH709 Hauora - Māori health issues. University of Otago.

Stewart-Harawira, M. (1997). The impact of the state-welfare relationship on whānau. In M. Olsen, \& K. Matthews (Eds.). Education policy in New Zealand: The 1990's and beyond. Palmerston North: Dunmore Press

TVNZ. (2007). Urgent calls for abuse inquiry, July 30 2007. Retrieved from http://tvnz.co.nz/view/ page/ $488120 / 1258488$. 